
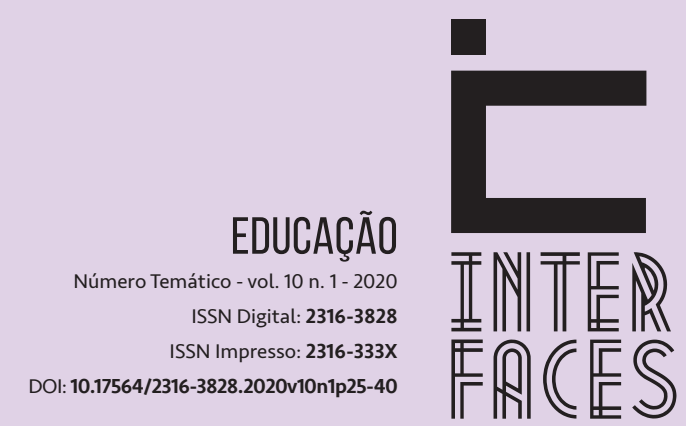

CIENTÍFICAS

\section{EDUCAR NA INCERTEZA E NA URGÊNCIA: IMPLICACOÕES DO ENSINO REMOTO AO FAZER DOCENTE E A REINVENÇ̃̃O DA SALA DE AULA}

\section{EDUCATE IN UNCERTANTY AND URGENCY: MPLICATIONS OF REMOTE TEACHNG WHEN DONGG TEACHERS AND THE REINVENTION OF THE CLASSROOM}

EDUCAR EN LA INCERTIDUMBRE Y LA URGENCIA: IMPLICACIONES DE LA ENSEÑANZA REMOTA AL HACER PROFESORES Y LA REINVENCIÓNDEL AULA

Sidmar da Silva Oliveira Obdália Santana Ferraz Silva ${ }^{2}$ Marcos José de Oliveira Silva ${ }^{3}$

\section{RESUMO}

Este texto propõe uma reflexão sobre os desafios enfrentados por professores da Educação Básica, ao vivenciarem a experiência com o ensino remoto, mediado, especialmente, pelas tecnologias digitais (TD), dada a necessidade de distanciamento social, provocado pela covid-19. Trata-se de um estudo netnográfico que problematiza os desafios gerados pela necessidade de reorganizar a prática pedagógica, em função da suspensão das aulas presenciais, por causa da pandemia do coronavírus. Para tanto, realizamos uma roda de conversa com 12 professores da Educação Básica, por meio da plataforma Microsoft Teams. Este estudo toma como base autores que discutem sobre tecnologias digitais e formação docente, prática pedagógica potencializada pelas tecnologias digitais, ensino remoto e desafios à educação, a partir de artigos e vídeos já socializados na internet, pelos sites e redes sociais. 0 diálogo com os professores, atores desse processo, levou ao entendimento de que as tecnologias em si não promovem a produção do conhecimento, nem o aprendizado, pois é preciso uma reconfiguração das práticas pedagógicas para a potencialização da interação entre os sujeitos envolvidos no processo de ensino e aprendizagem. Quiçá, as vivências com o ensino remoto possam dar um impulso para se pensar essa prática mediada pelas TD, mas também possibilidades para além delas.

\section{PALAVRAS-CHAVE}

Tecnologias Digitais. Formação de Professores. Ensino Remoto. Educação Básica. 


\section{ABSTRACT}

This text proposes a reflection on the challenges faced by Basic Education teachers, when experiencing the experience with remote education, mediated, especially, by digital technologies (TD), given the need for social distance, caused by the covid-19. It is a netnographic study that problematizes the challenges generated by the need to reorganize the pedagogical practice, due to the suspension of face-to-face classes, because of the Coronavirus pandemic. To this end, we conducted a conversation with 12 teachers of Basic Education, through the Microsoft Teams platform. This study is based on authors who discuss digital technologies and teacher training, pedagogical practice enhanced by digital technologies, remote teaching and challenges to education, from articles and videos already socialized on the internet, through websites and social networks. The dialogue with the teachers, actors in this process, led to the understanding that the technologies themselves do not promote the production of knowledge or learning, as it is necessary to reconfigure pedagogical practices to enhance the interaction between the subjects involved in the teaching process. and learning. Perhaps, experiences with remote education may give an impulse to think about this practice mediated by TD, but also possibilities beyond them.

\section{KEYWORDS}

Digital technologies. Teacher Training. Remote Teaching. Basic Education.

\section{RESUMEN}

Este texto propone una reflexión sobre los desafíos que enfrentan los maestros de Educación Básica, cuando experimentan la experiencia con la enseñanza remota, mediada, especialmente, por las tecnologías digitales (TD), dada la necesidad de distancia social, causada por la Covid-19. Es un estudio netnográfico que problematiza los desafíos generados por la necesidad de reorganizar la práctica pedagógica, debido a la suspensión de clases presenciales, debido a la pandemia de coronavirus. Con este fin, mantuvimos una conversación con 12 profesores de Educación Básica, a través de la plataforma Microsoft Teams. Este estudio se basa en autores que discuten las tecnologías digitales y la formación del profesorado, la práctica pedagógica mejorada por las tecnologías digitales, la enseñanza remota y los desafíos a la educación, desde artículos y videos ya socializados en Internet, a través de sitios web y redes sociales. El diálogo con los docentes, actores en este proceso, permitió comprender que las tecnologías en sí mismas no promueven la producción de conocimiento o aprendizaje, ya que es necesario reconfigurar las prácticas pedagógicas para mejorar la interacción entre los sujetos involucrados en el proceso de enseñanza y aprendizaje. Quizás, 
las experiencias con la educación remota pueden dar un impulso para pensar en esta práctica mediada por TD, pero también posibilidades más allá de ellas.

\section{PALABRAS CLAVE}

Tecnologías digitales. Formación de profesores. Enseñanza remota. Educación Básica

\section{INTRODUCÇÃO}

A sociedade contemporânea enfrenta mudanças intensas nas mais diversas áreas da atividade humana, causadas pela crise da pandemia do coronavírus, incidindo inclusive na área educacional. Nesse processo a educação se vê na urgência de reinventar-se para acompanhar essas transformações, e, ao mesmo tempo, precisa pensar numa nova concepção da ação pedagógica, de sala de aula.

Tal fato aponta para uma necessária reflexão sobre como será, pós-pandemia, a estrutura da instituição educacional e dos programas que promovem a formação inicial e permanente dos professores. Considerando a relevância desse campo de estudo e pesquisa, o presente artigo trata de uma pesquisa bibliográfica e de campo sobre a problemática que envolve o ensino remoto ${ }^{4}$ e a formação de professores para a integração das Tecnologias Digitais (TD) em suas práticas pedagógicas.

A propagação acelerada da Covid-195 tem exigido medidas importantes por parte dos governantes brasileiros e de todo o mundo, visando ao enfrentamento, adaptação e prevenção da doença em todos os âmbitos da vida humana, inclusive na educação. As consequências, impactos e implicações sobre a sociedade são significativos e ainda não foram dimensionados na sua totalidade. A suspensão das aulas presenciais, no ensino básico e superior, pela urgência de se estabelecer o distanciamento social ${ }^{6}$, tem se constituído como solução mais urgente para proteger alunos e profissionais da educação, reduzindo as chances de que se tornem transmissores do vírus em suas famílias e comunidades.

A sala de aula, por ora fechada, já não pode ser entendida apenas como espaço físico, com alunos e carteiras enfileiradas ou em círculo. Na prática, esse cenário tem inquietado professores, familiares e gestores, que tentam dar continuidade ao processo educacional, mediados pelas Tecnologias da Informação e Comunicação (TIC), em especial, as digitais. Entra em cena, o ensino remoto emergencial, que exige que gestores, coordenadores e professores se posicionem e ajam na intenção de adaptar

\footnotetext{
4 Não é nosso objetivo discutir, neste texto, a diferença entre ensino remoto e educação à distância. Entretanto, esclarecemos que a expressão ensino remoto, que caracteriza as ações pedagógicas rápidas de professores, mediados pelas tecnologias digitais, nesses tempos pandêmicos, não pode se confundir com a educação à distância, uma vez que esta possui uma estrutura sistemática, princípios definidos, que preconizam um modelo virtual de ensino e aprendizagem ancorado em um design instrucional/educacional centrado no desenvolvimento de competências e em princípios como o construtivismo, a autonomia, a interação e a colaboração. 50 site https://coronavirus.saude.gov.br/ conceitua a Covid-19 como uma doença causada pelo coronavírus SARS-CoV-2, que apresenta um quadro clínico o qual varia de infecções assintomáticas a quadros respiratórios graves, podendo necessitar de suporte para o tratamento de insuficiência respiratória (suporte ventilatório).

6 Separação de indivíduos ou grupo do convívio com o restante da sociedade para diminuir a velocidade de transmissão da Covid-19.
} 
conteúdos curriculares, dinâmicas de sala, até avaliações, visando dar continuidade a aulas, mediados por tecnologias digitais. Nesse modelo de ensino,

[...] gestores, professores, pais e alunos, desenvolvem outros esquemas para garantir o trabalho e o estudo remotos, para ampliar os limites das escolas por meio de atividades online. Mesmo diante da precária inclusão digital no Brasil e das desconfianças de muitos, a Internet se tornou a tecnologia interativa por meio da qual, de muitas e criativas maneiras, milhares de crianças, jovens e adultos continuaram e continuam a ensinar e aprender nesses tempos conturbados. (COUTO; COUTO; CRUZ, 2020, p. 212).

Essa mudança exige reflexões epistemológicas sobre os novos rumos do processo ensino e aprendizagem e nos levam a questionar: que desafios tem enfrentado a Educação Básica, dada a necessidade de se lançar mão do ensino remoto, a partir do uso das tecnologias digitais, visando à reinvenção da prática pedagógica convocada pelo contexto atual?

A reflexão sobre essa temática nos leva a entender que muitos são os desafios que a mediação tecnológica coloca ao professor, na reorganização de sua prática pedagógica, pois o uso dos aparatos tecnológicos, das plataformas, das redes traz implicações às metodologias empregadas. A educação retardou o processo de integração das TD às práticas pedagógicas, o que pode se caracterizar como obstáculo à articulação dessas tecnologias às práticas escolares cotidianas.

Serve-nos, hoje, a metáfora usada por Lévy (1999, p. 150), há 21 anos, para falar das emoções desencadeadas no ser humano pelo virtual, frente à revolução causada pela inteligência coletiva e a perplexidade do homem diante das gigantescas redes:

Seres humanos, pessoas daqui e de toda parte, vocês que são arrastados no grande movimento da desterritorialização, [...] vocês que pensam reunidos e dispersos entre o hipercórtex das nações, vocês que vivem capturados, esquartejados, nesse imenso acontecimento do mundo que não cessa de voltar a si e de recriar-se, vocês que são jogados vivos no virtual, vocês que são pegos nesse enorme salto que nossa espécie efetua em direção à nascente do fluxo do ser, sim, no núcleo mesmo desse estranho turbilhão, vocês estão em sua casa. Bem-vindos à nova morada do gênero humano. Bem-vindos aos caminhos do virtual!

De fato, as sucessivas mudanças que marcam o mundo, na atualidade, têm servido para reafirmar a necessidade de se produzir novas formas de ensinar e de aprender, por meio das TD, de se reinventar a sala de aula. Os professores foram “jogados vivos no virtual!", para aprender a fazer em serviço, enfrentando os milhões de alunos - e também professores - excluídos digitalmente. 0 caminho é longo e há professores que ainda esperam a aula começar entre paredes, porque ainda não conseguiram situar-se na rede, limitados, também, pela questão da conectividade.

Não obstante, não se pode voltar atrás, porque o avanço tecnológico que ganhou notoriedade com o advento e expansão das TD vem modificando, cada vez mais, as formas de comunicação e interação entre as pessoas e o momento atual nos revela que as TD não são mais apenas 
uma opção, no contexto educacional. As mudanças que, querendo ou não, atravessam o contexto escolar por meio da diversidade de culturas e de linguagens (ROJO, 2012), vivenciadas pelos alunos, em suas comunidades, não podem ser ignoradas pela escola, como instituição responsável pela formação cidadã dos sujeitos.

As discussões sobre a integração das TD ao processo educacional têm ganhado uma atenção especial em diversos estudos e pesquisas stricto sensu e, durante esse período de pandemia de covid-19, tem sido o foco dos debates educacionais em lives, videoconferências, rodas de conversa e reuniões virtuais, realizadas em diversas plataformas. Diante dessa problemática, é essencial analisar o cenário atual por todos os ângulos e considerar três questões, que se conectam, quando falamos de ensino remoto: o acesso à internet; a qualidade dos artefatos tecnológicos de alunos e professores; e domínio e formação para o uso desses artefatos.

Diante da nova realidade imposta pela Covid-19, cabe questionarmos não somente acerca do acesso às tecnologias, mas, sobretudo, da possibilidade de serem ofertadas a professores e alunos condições para uso pleno dos recursos tecnológicos, de modo a favorecer uma aprendizagem interativa e colaborativa. Sabemos que são muitos os desafios e os fatores implicados, desde a falta de estrutura tecnológica das escolas, formação dos próprios professores e alunos para um uso crítico das tecnologias. (CANI et al., 2020, p. 24).

O professor, considerando todos esses desafios, mesmo agindo na incerteza e aprendendo na urgência, precisa ir à luta para garantir a todos o direito à aprendizagem, o que parece ainda não ter se concretizado no ensino, com a mediação das TD. Estas podem contribuir para transformar a escola em um espaço mais dinâmico, de pesquisas, de exploração de culturas e de novos aprendizados; mas, como diz Freire (2013), se forem alicerçadas pela ação dialógica entre educador-educando, a partir de seus contextos culturais e de suas lutas políticas cotidianas.

\section{PROCESSO METODOLÓGICO}

As discussões em torno do ensino remoto nos mobilizaram a realizar um estudo sobre os desafios colocados ao professor da Educação Básica, tendo em vista a necessidade de dar continuidade, nesse contexto de distanciamento social, ao processo de ensino e aprendizagem, mediado pelas TD. Para tanto, recorremos à netnografia, abordagem vinculada a um trabalho de campo on-line, que permite utilizar diferentes formas de comunicação mediada por tecnologias digitais para a construção de dados.

Para Kozinets (2014), a netnografia é uma forma adaptada da etnografia para estudar realidades e sujeitos em ambientes digitais, em fóruns de discussão, videoconferências, aplicativos colaborativos, blogs, redes sociais etc. Na prática, a netnografia não trata as comunicações on-line apenas como conteúdo ou formas, mas como interações sociais, com expressões tomadas por diversos significados e como artefatos culturais (KOZINETS, 2010). 
Realizamos uma roda de conversa on-line, com duração de cinco horas, tomando como orientação metodológica essa abordagem, por meio do Microsoft Teams ${ }^{7}$, com 12 professores-pesquisadores ${ }^{8}$ que atuam na Educação Básica de cidades do interior e da capital, para discussão do tema: dificuldades, desafios e aprendizados vivenciados por professores da Educação Básica, em tempo de covid-19. Com anuência dos partícipes, registramos e arquivamos as discussões realizadas sobre os desafios da prática pedagógica, mediada pelas TD, bem como outras questões que têm emergido nesse contexto de distanciamento social, que nos mobilizam a repensar as concepções de ensino, aprendizagem e sala de aula.

A escolha dos participantes desta pesquisa foi realizada da seguinte forma: um convite foi enviado aos participantes do Grupo de Estudo e Pesquisa em (Multi)letramentos, Educação e Tecnologias (GEPLET/UNEB-Salvador/Coité) que atuam como professores da Educação Básica e aos professores da Educação Básica, participantes de um projeto de extensão denominado “Com licenç@, posso entr@r? Formação docente para práticas de letramentos multi-hipermidiáticos na sala de aula: sob o olhar da diversidade e do lúdico”, realizado no município de Queimadas Bahia, como locus de pesquisa de um projeto de pós-doutorado.

É do nosso interesse apenas os professores que desenvolvem atividades remotas, no período da pandemia, dos membros do referido grupo que se disponibilizaram a participar deste estudo, foram selecionados seis professores que vivenciam os desafios do ensino remoto; dos professores que participam do projeto de extensão, também foram selecionados seis que estão desenvolvendo atividades remotas. Além disso, os referidos professores foram escolhidos por terem assumido o compromisso de realizar com os pesquisadores encontros virtuais, pela plataforma Microsoft Teams, para reflexão e diálogo sobre a temática em discussão neste texto.

Nessa perspectiva, justificamos a opção pela netnografia: o necessário uso do ambiente digital para propiciar interação e discussão entre os colaboradores da pesquisa e para construção dos dados, visando à compreensão do objeto estudado. Assim sendo, consideramos importante informar aos participantes os constituintes relevantes sobre a pesquisa, obter consentimento dos colaboradores, citar e dar o devido crédito aos membros (KOZINETS, 2014). Estes são passos relevantes na pesquisa netnográfica, com a devida observância aos princípios éticos que envolvem pesquisas com seres humanos.

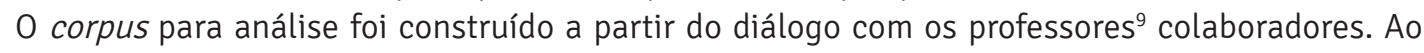
categorizarmos $^{10}$ o material produzido, destacamos alguns recortes discursivos desses professores, avaliados como de grande relevância para o alcance do objetivo proposto. 0 diálogo com os professores pôs em evidência algumas situações para análise e problematização: tecnologias digitais e formação continuada; acesso à internet, por professores e alunos; ensino remoto, seus desafios e possibilidades para se repensar mudanças na sala aula durante e pós-pandemia.

70 Microsoft Teams é uma plataforma unificada de comunicação e colaboração que combina bate-papo, videoconferências, armazenamento de arquivos e permite de modo simultâneo a interação entre os participantes.

8 Termos de cessão de direitos autorais foram assinados por todos os professores participantes.

9 Neste texto, as identidades dos sujeitos preservadas. Portanto, a eles nos referimos pelos seguintes pseudônimos os quais foram escolhidos pelos próprios sujeitos: Brutaflor, Zezinha, Kayla, Riobaldo, Dandara, Sésiom, Helena e Vida.

10 Para Moraes e Galiazzi (2016), categorizar é reunir o que é comum, que resulta em formação de conjuntos de elementos que possuem algo em comum. 


\section{TECNOLOGIAS DIGITAIS EM TEMPOS DE ENSINO REMOTO: POSSIBILIDADES E APRENDIZADOS}

Ensinar e aprender são processos que exigem constante ressignificação, e com as céleres mudanças que permeiam a sociedade atual, provocadas pelo advento das TD urge a necessidade de a escola repensar seus modos de atuação. Concordamos que este repensar perpassa pela integração dessas tecnologias ao fazer pedagógico, com vistas a uma formação que vise a uma nova ética e nova estética (ROJO, 2012), afinal de contas, vivemos uma era de mudanças frenéticas que demandam uma educação capaz de tornar os alunos "[...] aprendizes autônomos, críticos, bem informados, cooperativos, colaborativos e que saibam usufruir plenamente, com segurança e com responsabilidade, das oportunidades que lhes são oferecidas nos ambientes digitais” (COSCARELLI, 2018, p. 33-34).

Neste contexto de pandemia, os professores são mobilizados a conhecer e utilizar plataformas virtuais/digitais, que possibilitam aprendizagens colaborativas. Como enfatizam Cani e outros autores (2020, p. 26, grifos dos autores), "Mediante todos os 'bombardeios' provocados pela Covid-19, a educação precisou, em pleno século XXI, criar um ‘abrigo' elaborado e, com trabalhos de 'escavação', fazer 'trincheiras' para poder permitir a circulação do conhecimento, que não pode 'morrer”'.

É o enfrentamento de um risco que precisa ser entendido como ato político, sempre visando à autonomia e bem-estar dos sujeitos envolvidos no processo educacional. Agora, como já era antes da pandemia, "Os professores [...] têm que atuar como permanentes aprendizes e aprender a se comunicar na linguagem e estilo de seus estudantes” (PRENSKY, 2001, p. 4, grifos nossos). Isso exige deles repensar seus modos de atuação, compreender as TD para integrá-las ao ensino, utilizando-as de forma crítica, reflexiva e significativa. Da escola exige-se reestruturar seus projetos e propostas pedagógicas, estabelecer novos caminhos a partir dos já trilhados, tendo em vista que não se poderá negar mais que

O digital produziu uma mudança na discursividade do mundo [...] nas relações históricas, sociais e ideológicas, na constituição dos sujeitos e dos sentidos, mas também na forma dos relacionamentos, do trabalho, da mobilidade, dos encontros, até mesmo do fazer científico, do qual faz parte a maneira de sua produção e seus meios de circulação. (DIAS, 2016, p. 9).

O desafio do professor, portanto, é observar essas mudanças para compreendê-las, no âmbito de seu trabalho pedagógico, a fim de que possa ressignificá-lo, atualizá-lo. Isso exige um tempo mais longo para formação dos envolvidos no processo, com preparação de infraestrutura tecnológica que vise à aprendizagem. Entretanto, com a suspensão das aulas, o ensino remoto entra em cena como reposta à crise e o professor, sem tempo de parar para refletir, precisou agir na urgência.

Em um dos eventos pertencentes à série de webinários Educação no mundo 4.0, organizada pelo Ministério da Educação, o professor Seiji Isotani, do Instituto de Ciências Matemáticas e de Computação (ICMC - USP), em sua palestra, no dia 6 de maio de $2020^{11}$, cuja discussão era uso da tecnologia da informação e comunicação nas escolas de Educação Básica, destacou que

11 Esta palestra está disponível em: https://www.youtube.com/watch?v=f1qRWNRaH7k\&feature=youtu.be. Acesso em: 22 jun. 2020. 
Todas as iniciativas de ensino remoto utilizadas durante a luta contra a Covid-19 podem ser sementes para a transformação digital e cultural tão necessária no ensino, unindo práticas pedagógicas inovadoras, como o aprendizado híbrido e metodologias ativas, com tecnologias educacionais inteligentes, que potencializam as capacidades do aluno aprender e do professor inovar.

Espera-se que nesse novo cotidiano que o professor tem vivenciado durante a pandemia, ele se permita aprender, que essas vivências e experiências possam servir de mote para transformações digital e cultural tão necessárias e urgentes na Educação Básica. Haverá maior sentido se professores e alunos, além do acesso, saibam navegar e explorar as diversas potencialidades que as TD propiciam, promovendo práticas pedagógicas inovadoras e aprendizados híbridos. É preciso que o professor, presencialmente ou a distância, atue como propositor-mediador do conhecimento, a fim de fortalecer "[...] o potencial da escola como espaço formador e orientador para a cidadania consciente, crítica e participativa” (BRASIL, 2018, p. 62).

Por entendermos a necessidade de transgredir as práticas educacionais enraizadas no cotidiano escolar, especialmente, neste cenário de mudanças instantâneas, entendemos ser a formação continuada um processo basilar para subsidiar as reflexões teórico-práticas dos professores e direcioná-los a novas formas de atuação.

\section{FORMCAÇÃO) CONTINUADA DO PROFESSOR: FORMAR-SE PARA (TRANSJFORMAR}

Em um contexto educacional marcado por uma cultura movente, que exige a compreensão de que "ninguém se forma realmente se não assume a responsabilidade no ato de formar-se" (FREIRE, 2011, p. 102), o papel do professor, na sociedade digital, é marcado por grandes responsabilidades sociais e dele são requeridas determinadas funções que lhes convocam a agir de modo consciente e crítico. Os professores precisam, permanentemente, intensificar o pensamento interativo, complexo e transversal, que lhe instigue a criar novas dinâmicas de aprendizagem, sempre em plena construção. Esse processo exige reconfiguração dos cursos de formação de professores e demanda um novo olhar acerca da própria formação e sobre o processo de ensino e aprendizagem.

Nóvoa (2001) entende que, mais importante do que formar, é formar-se e que o aprender contínuo é essencial à profissão docente, sendo marcado pela própria pessoa do professor, como agente, entendendo a instituição escolar, como um espaço de crescimento profissional permanente. Então, podemos dizer que as ações de formação docente, tendo como pano de fundo a integração das TD ao fazer pedagógico precisam tomar a escola como principal locus de formação, em quer os professores atuem em constante colaboração.

A formação docente é entendida como ponto nodal para transformar os modos de atuação da escola, tomando-se como base o trabalho colaborativo no cotidiano escolar; pois, "a bagagem essencial de um professor adquire-se na escola, através da experiência e da reflexão sobre a experiência. 0 que dá sentido à formação é o diálogo entre os professores, a análise rigorosa das 
práticas e a procura colectiva das melhores formas de agir” (NÓVOA, 2011, p. 72, grifos do autor).

Nessa perspectiva, é vital planejar e efetivar ações de formação continuada com os professores, a partir de situações concretas e atuais, tendo como base a reflexão, investigação e a colaboração. Nessa perspectiva formadora, o trabalho do professor torna-se cada vez complexo. Por isso, “[...] é necessário repensar a formação dos professores para que possam enfrentar as novas e diversificadas tarefas que lhes são confiadas na sala de aula e além dela" (BRASIL, 2013, p. 171), de forma crítica e problematizadora, com vistas a possibilitar aos alunos a construção de competências e habilidades que os auxiliem a interagir e interpretar as múltiplas linguagens que compõem os diferentes gêneros textuais e discursivos (ROJO, 2012).

No cenário social atual, o professor foi chamado a lidar com essas múltiplas linguagens e com a complexidade de criar metodologias que demandam o uso das TD adaptado ao ensino remoto. Vê-se nessa contingência de lidar com uma nova temporalidade, com outras linguagens e com a certeza de que mesmo empreendendo todo o esforço possível, ainda lhe falta condições de propiciar a todos os alunos uma educação pautada nos princípios da inclusão e do respeito às diferenças.

\section{ENSINO REMOTO E IMPLICAÇÕES NA PRÁTICA DOCENTE: 0 QUE DIZEM OS PROFESSORES DA EDUCAÇÃO BÁSICA?}

De acordo com a edição 2018 da pesquisa TIC domicílios ${ }^{12}$, realizada pelo Centro de Estudos para o Desenvolvimento da Sociedade da Informação, o maior percentual da população brasileira conectada à internet encontra-se nas classes com melhor condição socioeconômica: A, 99\%; B, 94\%; e, C com $76 \%$. Por outro lado, os dados do levantamento em questão indicam que apenas $40 \%$ da população pertencente às classes D e E acessam a internet. Essa assertiva nos levar a pensar nos sujeitos excluídos do ensino remoto.

Esses dados ganham materialidade quando discutimos com professores da Educação Básica sobre os desafios vivenciados por eles, neste período de suspensão das aulas presenciais devido à pandemia. A professora Brutaflor ${ }^{13}$ revela o seguinte: "a dificuldade maior é acesso do meu aluno. $\mathrm{O}$ aluno não tem acesso a uma boa rede de internet; o Wi-fi, normalmente, é compartilhado com todos da família e dificulta o entendimento, o envio de documentos”. Esse depoimento evidencia que grande parte dos alunos dessa professora provém de famílias de baixa renda que não dispõem de uma boa rede de internet para a participação em um processo educativo mediado por tecnologias digitais.

Nessa mesma perspectiva, a professora Zezinha relatou: "a dificuldade que a gente encontrou, foi a dificuldade de acesso mesmo e nossos alunos... eles estão espalhados pelo menos em oito municípios [...]. Então o acesso desses alunos, às atividades, o retorno não foi como a gente queria, né?”

12 A pesquisa denominada TIC Domicílios - 2018 Domicílios está disponível em: https://cetic.br/pt/tics/domicilios/2018/ domicilios/. Acesso em: 29 jun. 2020.

13 Para preservação da identidade, os professores colaboradores são identificados, neste texto, com pseudônimos escolhidos por eles mesmos. 
Nesse caso, a dificuldade de acesso à internet interferiu diretamente no alcance dos objetivos de ensino da professora. Esse depoimento nos lembra que os artefatos tecnológicos não são instrumentos acessíveis a toda população, evidenciando o chamado tecno-apartheid (CANCLINI, 2015, p. 236).

As condições de renda e de vulnerabilidade socioeconômica, que implicam diretamente na falta de acesso à internet e a dispositivos digitais, revelam a necessidade de (re)pensarmos o ensino remoto como solução emergencial para a continuidade das atividades de ensino e aprendizagem. Chama atenção, nesse sentido, o discurso de Kayla:

Nesse momento de pandemia em que se precisou, a única alternativa que se tinha era o trabalho através da tecnologia. Nós ficamos... nós constatamos, na verdade, que não era possível porque... primeiro, porque nós... os meninos não estavam conectados; eles não tinham acesso; alguns não tinham acesso à internet; outros não tinham acesso, não tinham sequer o aparelho, nem o notebook, nem celular, nem coisa nenhuma.

Para esta professora os problemas enfrentados pelos estudantes estão relacionados à falta de acesso à internet e à falta de dispositivos como tablets, notebooks e computadores que os permitam acompanhar, de modo satisfatório, as discussões e atividades propostas no ambiente digital. Sabemos que o celular permite a portabilidade, interatividade social e individualidade (ALVES et al., 2019), mas entendemos que a limitação das telas e a capacidade de armazenamento, bem como as interfaces, comandos para edição e produção de textos, podem se configurar como dificuldades para os alunos realizarem as atividades educacionais.

Aliada às questões que envolvem o acesso à internet e aos artefatos digitais que os alunos dispõem para realizar as atividades pedagógicas, surge outra temática para reflexão: a formação dos professores. 0 diálogo com os colaboradores nos possibilitou compreender que as políticas públicas de formação docente não têm proporcionado, mesmo antes da pandemia, uma formação para a integração das TD ao fazer pedagógico. Para Riobaldo,

Talvez, se a gente tivesse ao longo do tempo planejado para que isso viesse a acontecer, hoje a gente já estaria fazendo uso dessas tecnologias e voltando essas tecnologias para atender aquilo que a gente deseja. Mas a gente não foi condicionada a isso, a gente não foi treinado, a gente não fez curso [...]. Então, a gente tá tentando se virar como pode.

Decerto, a formação pedagógica ou ações formativas que orientem os professores a transitarem de um modelo tradicional para uma abordagem integradora das TD como mediadoras da aprendizagem é um desafio à educação. Ao afirmar: “a gente não fez curso [...]. Então, a gente tá tentando se virar como pode", Riobaldo nos leva à reflexão sobre a necessidade de formação permanente para o professor e as condições de sua prática pedagógica: apesar dos limites e barreiras, ele segue realizando seu trabalho, muitas vezes, na improvisação que the for possível, tentando organizar seu trabalho pedagógico, mas sem tomar como base alguma metodologia 
mais adequada para o trabalho no espaço on-line; ou ainda, pode significar a transposição didática do que era presencial para o virtual, sem um conhecimento dos ambientes, também de metodologias que possam substanciar a práxis.

As ações formativas precisam considerar as múltiplas práxis docentes como elementos potenciais para a (re)construção de teorias e práticas, capazes de permitir ao professor a apropriação dos artefatos tecnológicos disponíveis em benefício do processo de ensino e aprendizagem. Nesses termos, a formação para a integração das tecnologias digitais aos processos de ensino e aprendizagem segue muito distante da realidade formativa docente, como relata a professora Dandara:

Anteriormente [antes da covid-19], não tinha nenhuma política de falar sobre a utilização das tecnologias, a não ser em trabalhos pontuais de pessoas que tinham domínio ou de pesquisadores, né, da área. Mas, uma política de formação para pensar as tecnologias nas práticas pedagógicas, a gente ainda não tinha visto.

No depoimento da professora, podemos interpretar a referência à necessidade de priorização, por parte dos órgãos públicos responsáveis, de ações formativas docentes nas políticas de incentivo de financiamento e de fomento, com vistas ao uso das tecnologias digitais nas práticas pedagógicas. 0 cenário atual demanda políticas de formação continuada com professores para apropriação das potencialidades das tecnologias digitais, com vistas a reconfigurar os modos de ensinar e de aprender. Certamente, "Isso implica uma mudança de mentalidade formativa diante da desafiadora realidade em que nos encontramos" (CAMPOS, 2007, p. 43), que é a de garantir a continuidade do processo de ensino e aprendizagem por meio das TD.

Utilizar as tecnologias digitais para ressignificar os modos de ensinar e aprender em um curto espaço de tempo, realmente, é desafiador como destaca o coordenador e professor Sésiom: "saber utilizar o computador não significa dizer que esse meio vai estar servindo para aquele propósito que eu desejo [...] isso se dá por uma construção histórica na qual as tecnologias passaram ao longo do tempo sendo negligenciadas".

O depoimento de Sésiom nos leva a pensar no fenômeno da apropriação tecnológica na sua dimensão humana; são processos situados na história e na cultura da sociedade; constitui-se, ao mesmo tempo do material e do simbólico e assim precisam ser compreendidas no âmbito educacional. Portanto, integrar as TD ao fazer pedagógico exige conhecimentos e saberes que possibilitem um olhar multidimensional sobre as diversas trilhas pelas quais elas possibilitam enveredar.

A complexidade que se impõe nesse momento, sobremaneira, é reflexo do fosso que existe entre a formação docente e o uso das tecnologias digitais como possibilidades pedagógicas. Entendemos que essa discrepância contribui para existência das dificuldades inerentes ao uso de diversas plataformas e serviços digitais, como também para o desinteresse por parte de professores, como revela o discurso da professora Zezinha: "Eu acho que o principal aprendizado que a gente tem é a constatação de que muito já deveria ter sido feito e não foi, né? Como a gente já vem discutindo muito aí nas lives, tem trinta anos que permite o ensino remoto, o ensino híbrido, mas que até então nada foi feito".

Interpretamos do relato de Zezinha que o uso das tecnologias digitais integrado aos processos pedagógicos não tem origem atualmente, é uma demanda antiga, que tem se intensificado por conta da necessidade de promover o ensino remoto em função da suspensão das aulas presenciais. 
A análise dos discursos dos professores, colaboradores deste estudo, indica que o desenvolvimento tecnológico tem provocado mudanças significativas na sociedade e adentrado na escola. Mas, de acordo com Alves e outros autores (2019, p. 119) “o ambiente escolar ainda não dialoga com o mundo permeado pelas tecnologias digitais e seus dispositivos móveis”. Na prática, é perceptível que a escola não tem acompanhado e transformado os modos de atuação conforme a velocidade dos avanços tecnológicos.

Porém, há professores que têm se desafiado, buscando reinventar-se para acompanhar as transformações “Eu já trabalho, há muito tempo, na verdade, os três anos, com ensino híbrido, trabalhando com a sala de aula... é... usando o Google Sala de Aula, tentando melhorar, otimizar essa nova rotina para o retorno né... para o pós-pandemia" (Helena). Helena, como outros tantos professores tem se mostrado disponível a novos aprendizados, construídos a partir de sua curiosidade epistemológica, os quais podem contribuir para dinamizar e potencializar propostas de ensino e aprendizagem mediadas pelas TD, no pós-pandemia.

O ensino híbrido, presente no discurso de Helena, mescla o modelo presencial, tradicional, com estudos on-line, mediados pelas tecnologias digitais. Esse formato altera a dinâmica professor-aluno, uma vez que mobiliza os aprendentes a se envolverem bem mais com os processos de busca, exploração e produção do conhecimento, fatores preponderantes para o desenvolvimento da autoria discente.

Sobre isso, a professora Vida declara: "Eu acho que nunca a gente teve tanto assim, eu costumo dizer que a autoria. [...] Eu digo, poxa, eu nunca imaginei que ele fosse produzir tão bem né, seja a produção de texto, seja a produção de vídeos, seja, enfim, a produção de um meme”.

Nesse sentido, o ensino remoto, no contexto atual, pode impulsionar a construção de uma aprendizagem significativa e autônoma, uma vez que as tecnologias digitais podem ser usadas em várias propostas "em que os alunos vão lidar com diferentes recursos para trabalhar com imagens, filmes, áudios, nas quais eles serão encorajados a fazer suas próprias produções, aprimorando o letramento digital e promovendo a autoria e a cidadania" (COSCARELLI, 2019, p. 68). Para isso, é preciso que o professor assuma a responsabilidade de propor e mediar atividades que auxiliem o aluno a desenvolver produções autorais.

Nesse contexto, outras interfaces de ensino têm emergido, como relata a professora Dandara: “a minha impressão é que as redes sociais é hoje uma das ambiências formativas que temos, tanto falando na questão pedagógica de aprendizado, de postura, de conexão [...]”. De fato, as redes sociais possibilitam a interação e a colaboração de maneira rápida e com mobilidade em tempo real, possibilitando a construção de redes de conhecimento em espaços virtuais colaborativos e de entretenimento, como Instagram, WhatsApp e Facebook.

Nos relatos dos colaboradores deste estudo, o uso do WhatsApp como interface pedagógica tem sido bastante utilizado como podemos constatar no discurso da professora Vida: "Até o momento a gente só usa o WhatsApp, a gente tá vendo a possibilidade também de incluir outras plataformas [...] mas a gente percebe a necessidade também de ter outros elementos a mais e aí nós vamos começar a testar a partir de agora outras plataformas”. O professor tem usado WhatsApp pelo acesso rápido e fácil e consumo menor de dados da internet, além de ser do alcance de maioria dos estudantes.

Para Moran (2017, p. 3) "A combinação dos ambientes mais formais com os informais (redes sociais, wikis, blogs), feita de forma inteligente e integrada, nos permite conciliar a necessária organi- 
zação dos processos com a flexibilidade de poder adaptá-los à cada aluno e grupo". A convergência de plataformas e ambientes digitais com propósitos didáticos pode ser importante aliada dos professores, com vistas ao alcance dos propósitos pedagógicos.

Essas premissas levam-nos a pensar a respeito dos desafios e possibilidades para atender as demandas do ensino remoto em um país de grande dimensão continental e com diversas realidades socioeconômicas. É essencial levar em conta as desigualdades sociais que atravessam as redes de ensino e escolas, o acesso a internet e a formação dos professores, aspectos relevantes para a promoção do ensino mediado por tecnologias digitais.

\section{CONSIDERAÇÕES FINAIS}

Este estudo nos possibilitou realizar múltiplas interpretações sobre a integração das tecnologias digitais ao fazer pedagógico, possibilitando-nos compreender que há desafios a enfrentar em relação à promoção do ensino remoto, durante e pós-pandemia: distribuição de artefatos tecnológicos para estudantes de baixa condição socioeconômica; democratização do acesso à internet, possibilitando explorar plataformas ou ambientes virtuais de aprendizagem; a formação permanente dos professores para (re)construção de teorias e práticas necessárias à ressignificação da atuação docente, com vistas a atender as demandas da atualidade, relacionadas à integração das tecnologias digitais à prática pedagógica.

Tais demandas exigem dos professores da Educação Básica problematizar, mediar e incentivar a construção do conhecimento, com vistas à formação de sujeitos autônomos, autorais e capazes de contribuir para as transformações.

Entendemos que, considerando as dimensões epistemológicas, política, sociocultural e histórica das tecnologias digitais, estas podem se constituir para os professores, como uma possibilidade de produção de outros sentidos para a prática pedagógica, de modo a desconstruir um processo de significação estabilizado pelo fazer docente meramente técnico. Nesse sentido, urge que o professor redimensione sua ação docente e amplie sua práxis pedagógica para potencialização da interação entre os sujeitos aprendizes, com respeito às suas linguagens e culturas, visando a um agir mais ético e sensível às questões humanas.

Deste modo, se as tecnologias digitais nas escolas forem direcionadas para fins pedagógicos que contribuam com o desenvolvimento intelectual e cultural dos alunos, estarão contribuindo impreterivelmente numa nova forma de concepção de currículo, de organização escolar, de tempo e espaço, redimensionando o olhar de todos os envolvidos no processo educativo. Cabe ressaltar que o essencial não é a tecnologia em si, mas sim a necessidade de reconfigurar, de ampliar e criar práticas pedagógicas que potencializem a interação entre os envolvidos nos processos de ensino e aprendizagem. 


\section{REFERÊNCIAS}

ALVES, Lynn (et al). Tecnologias digitais nos espaços escolares: um diálogo emergente. In: FERRAZ, Obdália (org.). Educação, (multi)letramentos e tecnologias: tecendo redes de conhecimento sobre letramentos, cultura digital, ensino e aprendizagem na cibercultura. Salvador: EDUFBA, 2019. p. 117-139.

BRASIL. Base Nacional Comum Curricular: educação é a base. Brasília: MEC/SEB, 2018.

BRASIL. Diretrizes Curriculares Nacionais da Educação Básica. Brasília: MEC/SEB, 2013.

CAMPOS, Casemiro de Medeiros. Saberes docentes e autonomia dos professores. Petrópolis, RJ: Vozes, 2007.

CANCLINI, Néstor Garcia. Diferentes, desiguais e desconectados: mapas da interculturalidade. 3. ed. Rio de Janeiro: Editora UFRJ, 2015.

CANI, Josiane Brunetti; SANDRINI, Elizabete Gerlânia Caron; SOARES, Gilvan Mateus; SCALZER, Kamila. Educação e covid-19: a arte de reinventar a escola mediando a aprendizagem "prioritariamente" pelas TDIC. Revista IfesCiência, v. 6, Edição Especial, n. 1, 2020, p. 23-39. Disponível em: https://ojs.ifes.edu. br/index.php/ric/article/download/713/484. Acesso em: 22 jun. 2020.

COSCARELLI, Carla Viana. Perspectivas culturais de uso de tecnologias digitais e a educação.

Revista Brasileira de Alfabetização, Belo Horizonte-MG, v. 1, n. 8, p. 33-56| jul./dez. 2018. Disponível em: http://abalf.org.br/revistaeletronica/index.php/rabalf/article/view/293/211. Acesso em: 3 maio 2020.

COSCARELLI, Carla Viana. Multiletramentos e empoderamento na educação. In: FERRAZ, Obdália (org.). Educação, (multi)letramentos e tecnologias: tecendo redes de conhecimento sobre letramentos, cultura digital, ensino e aprendizagem na cibercultura. Salvador: EDUFBA, 2019. p. 61-77.

COUTO, Edvaldo Souza; COUTO, Edilece Souza; CRUZ, Ingrid de Magalhães Porto. \#Fiqueemcasa: educação na pandemia da covid-19. Interfaces Científicas, Aracaju, v. 8, n. 3, p. 200-217, 2020.

DIAS, C. A análise do discurso digital: um campo de questões. Revista Eletrônica de Estudos do Discurso e do Corpo - REDISCO, Vitória da Conquista, v. 10, n. 2, p. 8-20, jul.-dez. 2016. Disponível em: http://periodicos.uesb.br/index.php/redisco/article/viewFile/6139/5880. Acesso em: 20 maio 2017. 
FREIRE, Paulo. A importância do ato de ler: em três artigos que se completam. 51. ed. São Paulo: Cortez, 2011.

FREIRE, Paulo. Pedagogia do oprimido. 55. ed. Rio de Janeiro: Paz e Terra, 2013.

KOZINETS, Robert V. Netnografia: a arma secreta dos profissionais de marketing: como o conhecimento das mídias sociais gera inovação. 2010. Disponível em: http://kozinets.net/wpcontent/uploads/2010/11/netnografia_portugues.pdf. Acesso em: 22 maio 2020.

KOZINETS, Robert V. Netnografia: realizando pesquisa etnográfica online. Porto Alegre: Penso, 2014.

LÉVY, Pierre. 0 que é o virtual? São Paulo: Editora 34, 1999.

MORAES, Roque; GALIAZZI, Maria do Carmo. Análise textual discursiva. 3. ed. ljuí: Editora Unijuí, 2016. (Coleção educação em ciências).

MORAN, José. Metodologias ativas e modelos híbridos na educação. In.: YAEGASHI, Solange e outros (org.). Novas Tecnologias Digitais: Reflexões sobre mediação, aprendizagem e desenvolvimento. Curitiba: CRV, 2017, p.23-35. Disponível em: http://www2.eca.usp.br/moran/wpcontent/uploads/2018/03/Metodologias_Ativas.pdf. Acesso em: 27 jun. 2020.

NÓVOA, António. 0 regresso dos professores. Lisboa: Universidade de Lisboa, 2011.

NÓVOA, António. Professor se forma na escola (online). Revista Nova Escola, São Paulo, n. 142, v. 16, p. 13-15, maio 2001.

PRENSKY, Marc. Nativos digitais, imigrantes digitais. De On the Horizon, v. 9, n. 5, 2001. Disponível em: www.colegiongeracao.com.br/novageracao/2_intencoes/nativos.pdf. Acesso em: 18 maio 2020.

ROJO, Roxane. Pedagogia dos multiletramentos: diversidade cultural e de linguagens na escola. In: ROJO, Roxane; MOURA, Eduardo (org.). Multiletramentos na escola. São Paulo: Parábola Editorial, 2012. 
1 Mestre em Educação e Diversidade pela Universidade do Estado da Bahia - UNEB; Professor da Educação Básica; Atualmente exerce a função de gestor escolar.

E-mail: sydy.oliveira10@gmail.com

2 Doutora em Educação pela Universidade Federal da Bahia; Mestre em Educação e Contemporaneidade pela Universidade do Estado da Bahia - UNEB; Professora da Universidade do Estado da Bahia e dos Programas de Pós-graduação Educação e Diversidade - MPED/UNEB e Educação e Contemporaneidade - PPGEDUC/UNEB. E-mail: bedaferraz@hotmail.com

3 Especialista em Metodologia do Ensino Superior e EaD pela Faculdade Educacional da Lapa;Mestrando em Educação e Diversidade pela Universidade do Estado da Bahia UNEB; Técnico em Assuntos Educacionais da Universidade Federal do Recôncavo da Bahia - UFRB.

E-mail: marcosjose4230@gmail.com

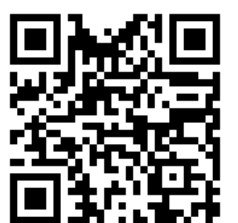

A autenticidade desse artigo pode ser conferida no site https://periodicos. set.edu.br

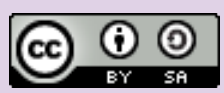

Este artigo é licenciado na modalidade acesso abertosob a Atribuição-Compartilhalgual CC BY-SA

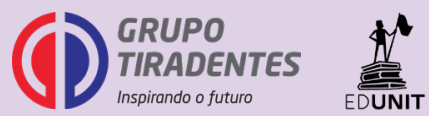

